\title{
Sentidos del escribir ${ }^{1}$
}

Meanings of writing

Carlos Skliari

CONICET, Argentina / FLACSO, Argentina

\section{Resumen}

Este artículo pone de relieve la cuestión del "sentido" de la escritura, del "sentido" del escribir. Aunque tal vez el único "sentido", la única razón de la escritura sea escribir, sin tener razones para hacerlo, ni de antemano ni a posteriori, ni razones mayúsculas ni razones minúsculas. Ni escribir para ser alguien en el mundo, ni para el futuro, ni para el porvenir, ni para la posteridad; ni para asumir una posición desde la cual ver el mundo, ni para autorizar a que otros tomen ésas u otras posiciones, ni para avanzar en la vida, ni para retroceder. Ni para ser mejor o peor persona.

Palabras clave: escritura, razón pedagógica, razón literaria, escribiendo.

\section{Abstract}

This paper focus on the issue of the "meaning" of writing, the "meaning" in writing. Although perhaps the only "meaning", the only reason for writing is to write, without having reasons to do it, neither before nor after it, having neither major nor insignificant reasons. Writing neither to be someone in the world nor to the future, to the posterity; neither to assume a perspective from which the world can be seen, nor to allow others to assume these or those perspectives, neither to advance in life nor to reverse. Not even to be a better or a worse person.

Keywords: writing, pedagogic reasoning, literary reasoning, writing.

\section{Introducción}

En la escritura no hay otra razón que el amor y al desamor por las palabras, la pasión y al desasosiego por las palabras, la atracción y la repulsión por las palabras:

Un escritor sería (...) alguien que otorga particular importancia a las palabras; que se mueve entre ellas tan a gusto, o acaso más, que entre los seres humanos; que se entrega a ambos, aunque depositando más confianza en las palabras; que destrona a éstas de sus sitiales para entronizarlas luego con mayor aplomo; que las palpa y las interroga; que las acaricia, lija, pule y pinta, y que después de todas estas libertades íntimas es incluso capaz de ocultarse por respeto a ellas. Y si bien a veces puede parecer un malhechor para con las palabras, lo cierto es que comete sus fechorías por amor (CANETTI, 1999, p. 82).

\footnotetext{
${ }^{1}$ Este texto se origina en el proyecto de investigación "Argumentos pedagógicos y literarios para la escritura y la lectura", desarrollado entre 2012 y 2015 en el Consejo Nacional de Investigaciones Científicas y Tecnológicas de Argentina.
} 
Pero no está demás decir que se escribe no para algo, sino para alguien, no en nombre de algo, sino en nombre de alguien. $Y$ que en ese alguien hay una mezcla de presencia con nombre propio y ausencia, quizá, sin nombre alguno. Que se escribe para uno y para otro: "Desde luego, escribimos, en primer lugar, para nosotros, para aclararnos, para tratar de elaborar el sentido o el sinsentido de lo que nos pasa. Pero hay que escribir, también, para compartir, para decirle algo a alguien, aunque no lo conozcamos, aunque quizá nunca nos lea" (LARROSA, 2011, p. 202).

Para ser escritor hay que escribir, a lo que se podría añadir: para escribir hay un cierto grado de renuncia, de dejar de ser, de darse de bruces con la imposibilidad de hacerlo, de estar del lado de la desazón, del hastío, del tener paciencia, del quedarse en medio del peligro de la escritura, de la soledad, de la desesperación, del quitarse de la cabeza que es posible aprender a escribir.

Entonces sí, escribir.

Escribir, entonces, no es. Escribir, hay.

O, dicho en otro sentido: la escritura no es. En la escritura, hay: "Y ya que hay que escribir, que al menos no aplastemos con palabras las entrelíneas" (LISPECTOR, 2007, p. 27).

\section{La escritura ya no es lo que era}

La escritura ya no es lo que era. Lo que no está ni mal ni bien. Sólo se trata de preguntarse si aún vale la pena darle algunas vueltas a qué era la escritura que ahora no es, a qué es esa escritura que ahora está. Lo que estaría mal sería encogerse de hombros en señal de que así son las cosas. Lo que sería mejor es declinar de la idea que sin escritura nos transformamos en animales dóciles, o en humanos aberrantes, incompletos.

Ya sabemos lo que provoca la domesticación a través del lenguaje como estandarte, como bandera. Una de las preguntas que, creo, valen la pena hacerse es aquella del humanismo vinculado a la escritura. Esa pregunta encuentra aquí - por cierto fuertemente inspirada por algunas ideas del filósofo Peter Sloterdïjk - dos direcciones posibles: la vaga noción de cofradía o de comunidad o de amistad que la escritura produce; y la afirmación de la escritura como norma. Ambas ideas provienen, en efecto, de la historia del humanismo, pero en diferentes tiempos.

En primer lugar podríamos identificar la historia del humanismo con la historia de la escritura: la escritura como una suerte de carta universal que va pasando de generación en generación gracias a un pacto íntimo y secreto entre emisarios y destinatarios, originales y copias, un vínculo férreo para poder ir más lejos, para no encerrarse, para poder realizar travesías propias y ajenas. Una travesía de ese porte suponía y supone 
tanto al escritor como al lector. Y esa es la principal virtud de una amistad que durará siglos.

Hay en esta apreciación un eco de aquel Nietzsche que buscaba transformar el amor al prójimo - ese amor tan inmediato, tan religioso, tan mezquino - en un amor por vidas ajenas, lejanas, desconocidas. Y esa transformación nos era dada gracias a la escritura. La escritura, entonces, como invitación a ir más allá de uno mismo, a salirse, a quitarse la propia modorra, una invitación para abandonar el relato repetido, la identidad del uno como centro de gravedad y como centro del universo.

La imagen es conocida y aún así no deja de ser curiosa y amable: un fantasma comunitario está en la base de todos los humanismos, una suerte de sociedad literaria devota e inspirada, en fin, una comunión en armonía. Permanezcamos un poco más en esta imagen y encontremos su contra-cara. Antes, mucho antes de la llegada de eso que hoy llamamos - no sin cierta levedad- el Estado, o mejor aún, el Estado Nacional saber leer y escribir supondría:

\begin{abstract}
Algo así como ser miembro de una elite envuelta en un halo de misterio. En otro tiempo, los conocimientos de gramática se consideraban en muchos lugares como el emblema por antonomasia de la magia. De hecho ya en el inglés medieval se derivó de la palabra grammar el glamour; a aquel que sabe leer $y$ escribir, también otras cosas imposibles le resultarán sencillas. Los humanizados no son en principio más que la secta de los alfabetizados, y al igual que en otras muchas sectas, también en ésta se ponen de manifiesto proyectos expansionistas $y$ universalistas (SLOTERDIJK, 2006, p. 24).
\end{abstract}

Subrayemos algunas palabras de este fragmento, por ejemplo: elite, misterio, magia, glamour, secta. Es inmediata la sensación de un mundo partido, quebrado o dividido en función o en virtud o en el privilegio de la escritura y la lectura. Lo que no hace más que devolvernos a la creencia platónica de una sociedad en la cual todos los hombres son animales - lo que no deja de ser cierto - pero donde algunos crían a los otros y estos otros serán, siempre, los criados. Para decirlo de otra manera: los animales que leen y escriben educan a los animales que no lo hacen.

Por lo tanto: el humanismo de los siglos XIX y XX se hizo pragmático, el pragmatismo induce a lo programático y esa sociedad sectaria, mágica, creció hasta volverse una norma para la sociedad política: "A partir de ahí los pueblos se organizaron a modo de asociaciones alfabetizadas de amistad forzosa, unidas bajo juramento a un canon de lectura vinculante en cada espacio nacional. ¿Qué otra cosa son las naciones modernas sino eficaces ficciones de públicos lectores que, a través de unas mismas lecturas, se han convertido en asociaciones de amigos que congenian?" (SLOTERDIJK, 2006, p. 25-26).

Revista Digital do LAV - Santa Maria - vol. 9, n. 2, p. 45 - 60. - mai./ago. 2016 ISSN 1983 - 7348 
Ese humanismo, el humanismo de Estado es el origen de la imposición de la lectura y la escritura obligatoria: los clásicos, el canon, el valor universal de los textos nacionales. Ya tendríamos a disposición algunos argumentos para desentrañar tanto la vertiginosa actualidad de la escritura como una insistente impotencia. Las ideas del humanismo ya no pueden contra la época actual; no pueden, no tienen lugar, no caben, son anacrónicas.

En buena medida porque también la escritura y la lectura se han transformado en mercancías y ya no requieren de lectores o escritores amables o amigos, sino de consumidores.

\section{La pregunta por la escritura}

La cuestión es la escritura. Lo que ya sabemos y lo que no sabemos sobre la escritura. Lo que se da por sentado y lo que nunca se reduce a una lógica previa en la escritura. La escritura en medio de la educación, como si fuera evidente que allí debiese estar, como si jamás fuera lo suficientemente obvio como para que allí permanezca.

Pedir la escritura, enfatizar la importancia de lo escrito, predicar sin demasiados ejemplos a la vista. La escritura compartida. Enseñada. Privilegiada. Escribir y leer se han vuelto acciones tan evidentes, que ya parece no haber margen para seguir pensándolo, para volver a pensarlo: didácticas, buenas prácticas, planes nacionales, bibliotecas, cuadernos, pizarras, computadoras, teléfonos celulares, libros, partes de libros, partes de partes de libros, apuntes, párrafos, letreros, mensajes, etc. De pequeñísimos a grandotes. Desde casi el nacimiento hasta la hora de la despedida.

Todo parece recubrirse de escritura y de lectura. Y sin embargo: ¿se trata de un camino que ya ha perdido su rumbo o de una forma de comunidad que aún persiste?

En términos educativos es difícil, sino imposible, separar cierta moralidad de lo útil, de lo necesario y de lo imprescindible. En términos culturales también lo es. Quizá se trate de adivinar algo de estos tiempos: discernir entre lo actual, la novedad, lo novedoso y lo contemporáneo. En educación parece que siempre vamos detrás de la novedad y lo novedoso; que no coincidimos en definir lo actual -por lo singular, lo contingente, lo rugoso-; y que lo contemporáneo sólo surge como un campo de batallas.

¿Cómo poner la escritura en medio? ¿Qué escrituras? ¿Sólo las aquí y ahora presentes, las breves, las que responden a demandas, las que relacionan la escritura con el trabajo y no con la creación o con la singularidad o con la subjetividad o con la intimidad? ¿Todo escribir es equivalente?

Educar es poner en medio. Entre. Hacer cosas, juntos, entre nosotros y entre otros. Poner la escritura en medio es pensar algo distinto al registro, al archivo, la devolución irrestricta de lo aprendido o la escritura como un código cerrado para la evaluación.

Revista Digital do LAV - Santa Maria - vol. 9, n. 2, p. 45 - 60. - mai./ago. 2016 ISSN 1983 - 7348 
No parece ser interesante sostener apenas una discusión a partir de las imágenes de los copistas medievales, de los escribientes de convento o de los escribidores de ocasión. Hay algo más.

¿Pero qué, exactamente?

\section{Escribir como si fuera el fin del mundo}

De todas las razones y sinrazones que le asisten a la escritura -a la escritura que forma parte del cuerpo, no ese artificio del código suelto y absuelto de toda realidad-aquella de cantar o de moverse como si se tratara de un gesto pasional, sigue siendo la que mueve al mundo, la que le permite respirar, la que lo hace hondo y, quién sabe, trasmisible.

Es cierto: alguien podría decir: ¿qué necesidad hay de escribir hacia abajo, verticalmente, con tantos espacios en blanco, con tan pocas palabras, con esas palabras sustantivas, volviendo y revolviendo la sensibilidad original, la de las primeras cosas? Alguien podría preguntar: ¿para qué sostener esa voz temblorosa que no hace más que asumir los variados rostros del viento: la brisa, el silbido, el vuelo, la bruma, la niebla, el aire en los ojos? Alguien podría argumentar, todavía: ¿es posible revolucionar la vida, los cuerpos e incluso el lenguaje con la mirada limpia -oscuramente limpia- de la escritura, de los poemas?

Escribir, quizá, como si se tratara del fin del mundo. Como si ya no hubiera tiempo, ni palabras, sino un abismo existencial frente al cual solo cabe la escritura. Es sólo un punto de partida, tal vez apenas una imagen: escribir, quizá, como si ya no tuviéramos ni tiempo ni mundo. Pero es también una posición y una forma de exponerse: es en ese límite, en ese abismo, en ese último resuello donde vale la pena preguntarse sobre la palabra y sus gestos. La humanidad ha vivido ya varias experiencias como si se tratara del fin del mundo. En ocasiones se ha puesto de rodillas o, quizá, agazapada. Otras veces ha desplegado ese grito intraducible y desgarrador del límite. Y también se ha rebelado. La poesía, así en general, se convierte en una figuración posible de estos tres modos de habitar el como si se tratara del fin del mundo: la poesía como el resguardo de las tempestades, la poesía como vociferación extrema y la poesía como rebelión. Lo hace a su modo, claro está: sin pretensiones circenses ni de dominación, tímida a la vez que voraz, contagiosa como un canto que atraviesa las épocas y sostiene un lenguaje que de otro modo sería puro barullo, sonido incomprensible o silencio atroz.

$Y$ es que hay escrituras que se sitúan al borde los acantilados, escrituras que son como el fuego renaciente, escrituras que se sumergen en el mar, escrituras que se ahogan a sí mismas y escrituras que de tan certeras nos hacen hablar con su ritmo, su potencia y su misterio. 


\section{La escritura destruida}

Escribe Marlen Haushofer (2003, p. 17):

Un día, también habré dejado de sentir el leve pesar que esto me causa, e incluso habré olvidado lo que fue el asomo de un recuerdo. Y creo que es eso lo que me atemoriza. No hay nada más horrible que el olvido. Puedo imaginar cómo las líneas que hoy escribo harán revivir alguna vez todo esto, este día de septiembre con el hálito de un recuerdo al fondo. Pero dudo que un muerto pueda hacer despertar a la vida algo que está muerto.

Hay veces que las palabras son destruidas por las amnesias, las desapariciones, por la indiferencia o incluso por la propia decisión de quien escribe. Ser un lector tendrá que ver con sostener lo que otros han escrito: darle tiempo, lugar, respiración. Y si bien el tiempo hace estragos, es en el presente, en éste presente, donde todavía puede haber vida para la escritura.

Los argumentos del futuro del escribir y del leer se han desvanecido o ya no existen. La promesa de que la escritura y la lectura nos harán mejores -en el sentido más oscuro de lo mejor- parece no tomar cuerpo en ningún cuerpo. $Y$ es que sólo cuando se escribe y se lee, en ese preciso instante en que las hojas permanecen tensas y temblorosas, es que hay escritura y lectura.

La cuestión de la escritura, la lectura y la memoria no es un problema técnico, ni siquiera un problema de conocimiento: se trata de un dilema quizá moral. Sé que esta última palabra parece desusada, anacrónica, casi la última sobreviviente de un humanismo en extinción. Pero justamente es ella la que marca, la que define, la que incorpora esa relación tan íntima de quien escribe con su escritura. Hablo aquí de una moral corpórea, que no se resuelve apenas con el ejercicio o con la práctica, que no tiene que ver sólo con las formas en que hoy se resuelven o se discuten las grandes cuestiones de lo humano y lo educativo.

Para recordar lo escrito hay que dar la lectura. Y para ello habría que ponerse a pensar tanto en lo que está disponible como en aquello que ya no está, es decir, recuperar las palabras perdidas, abandonadas a su propia suerte, desestimadas en nombre del progreso, de la razón; esas palabras, esos textos, que el tiempo ha querido borrar, disimular, abandonar, olvidar.

Se trata del lenguaje y la memoria, pero también se trata de la pérdida del lenguaje y de la memoria. Y de las posibilidades de restitución, de recuperar algo de aquello que alguna vez fue nuestro. De intentar dar a quien padece el recuerdo de su propia lengua ahora casi perdida.

Hay quienes están entre niños, jóvenes y adultos que han perdido su escritura o nunca la han conquistado o entre quienes utilizan una escritura que otros subestiman o desprecian 
o, simplemente, ignoran. O entre aquellos que no la aprenden como dios manda. Pues bien:

No es la «facilidad» en el aprender -el hecho de que sea habitual hacerlo- lo que justifica un pensamiento sobre educación, sino la experiencia de su dificultad. De modo específico, se trata de una reflexión que toma como punto de apoyo y raíz de su argumento la experiencia humana, no de la normalidad, sino la de la excepcionalidad, entendida como experiencia de lo frágil y de lo vulnerable (BÁRCENA, 2012, p. 13).

Entre todas las razones del escribir y del leer, ciertas o inciertas, útiles o inútiles, posibles o imposibles, aquellas que tienen que ver con los cuerpos deshechos, destruidos, despreciados, conmueven particularmente: recordar lo perdido, lo cruelmente abandonado, lo que se extingue y desaparece; poner de relieve lo que parece hundirse; escribir con la mirada de quienes se dice que no hablan o que aprenden, a partir de su propia y singular experiencia. Allí donde lo que permanece tal vez no sea el lenguaje metódico ni el aprendizaje ortodoxo, pero sí una absoluta vitalidad, tal como escribió de un modo sobrecogedor Tomas Transtömer, refiriéndose a su propio lenguaje dañado, en este fragmento:

Entonces llega el derrame cerebral: parálisis en el lado derecho/ con afasia, solo comprende frases cortas, / dice palabras inadecuadas. / Así no alcanzan ni el ascenso ni la condena. / Pero la música permanece, sigue componiendo en su propio / estilo (TRANSTÖMER, 2010, p. 68).

Escribir, indicar, mostrar la finitud, tocar la imposibilidad, balbucear, hacer la experiencia de lo frágil y lo vulnerable. Una escritura que se rebela y se retuerce para seguir andando. Deseando que algún día alguien la escriba. Alguien la lea.

\section{Escribir, escribiendo}

¿Qué es, qué podría ser: escribiendo?

Se trata de una pregunta del todo diferente a aquella de: ¿qué es escribir?, y también de aquella de: ¿qué es la escritura? Sobre esas dos últimas apariencias de la pregunta ya tenemos suficiente información, aún cuando sea ambigua y contradictoria y debamos distinguir, todavía, entre la racionalidad pedagógica y la racionalidad literaria.

Me parece que hay que preguntarse por la escritura a través de algunas prácticas, pero acentuando ese escribiendo como único tiempo posible, en el instante en que ocurre, en su duración: ¿qué puede significar escribiendo, qué es estar escribiendo, para estudiantes y profesores, escritores, escribientes, copistas y demás figuras que giran en torno de ella, en medio de prácticas de transmisión de saberes, valores, conocimientos, materias, currículo? 
No hay nada claro al respecto. Lo que sabemos es que se pide la escritura, que la escritura proviene por lo general de un pedido. Un pedido ya sea para relatar lo propio como para responder por un texto ajeno; un pedido ya sea para comentar o para definir; ya sea para elaborar como para puntualizar.

No puede dejar de sorprendernos, aún en su aparente habitualidad, esa relación entre escritura y petición. Por varios motivos: en principio porque ello sugiere que lo escrito tiene sólo un valor de respuesta; enseguida, porque me da la sensación que -de ser en efecto una respuesta o de tener apenas esa propiedad- no sabemos a qué con exactitud ¿a una pregunta escrita, o un texto leído, a un saber entregado, a una información solicitada, a una necesidad de completar una tarde, al puro y fresco deseo de que alguien se exprese con propiedad?; y por último: porque si la escritura fuese reducida a un mecanismo de intercambio estrecho, quedaría confinada al ejercicio de su corrección o de su adecuación y, por lo tanto, a la lógica de lo que es apropiado o inapropiado.

La escritura es petición, sí, pero también es reflejo del dominio o no, de la capacidad o no, de la diversidad o no, de las prácticas de escritura. En este sentido: ¿cómo valorar lo que se ha pedido? No queda más remedio, pareciera, que someterlo todo a la ecuación de lo mal o bien escrito, de lo correcto o incorrecto: el zoológico de los que cometen errores y la jauría de los que están al acecho para la corrección. ¿Pero dónde estaba y está, donde había quedado y permanece, qué era y es lo que se ofrece, lo que se da y no tanto lo que se peticiona y evalúa?

La escritura como petición se transforma en uno de los argumentos de autoridad más ambiguos y traicioneros. No crea un problema con la escritura sino con la autoridad. Como escribe Charles Dantzig (2011, p. 10):

Siempre he tenido un problema con la autoridad. Aún ahora, nada me indigna más que eso que se llama argumentos de autoridad, que consisten como es sabido en invocar una supuesta autoridad para acallar las preguntas. Se oponen al razonamiento, al maravilloso razonamiento, maravilloso porque se basa en la confianza. Los argumentos de autoridad se basan en el desprecio. Mi desconfianza en la autoridad tenía por contrapeso a la casi mágica confianza en lo escrito. Una frase, según el bárbaro en miniatura que era yo, sería una llave.

La escritura es petición, la escritura es constatación, pero también es la sombra o el contorno o la superficie de aquello que se ha entregado. Esa escritura pedida y evaluada no habla tanto de la escritura en sí como de la enseñanza, lo que hace tomar a este análisis una dirección completamente diferente. Es verdad que puedo comenzar por los textos escritos por los demás: compadecerme, incomodarme, asustarme, dar por sentada que así es, irremediablemente, la producción de esta época.

Revista Digital do LAV - Santa Maria - vol. 9, n. 2, p. 45 - 60. - mai./ago. 2016 ISSN 1983 - 7348 http://dx.doi.org/10.5902/1983734823512 
Lo que deberíamos hacer, me parece, es no omitirnos. No omitirnos del punto de partida: el modo en que nos relacionamos nosotros mismos con la lectura y la escritura. Pero: ¿en qué consistiría esa omisión? En verdad son muchas omisiones, ninguna de las cuales debe entenderse como acusación sin motivos: nuestra lectura cada vez más escasa, cada vez menos literaria y más mediática; los pactos cotidianos en torno a la brevedad y la fragmentación o reducción de los textos que se ponen juego en las prácticas institucionales; el desprecio por la escritura creativa, ensayada, libre de espíritu; la naturalización artificiosa que supone que buscar es ir hacia los motores de búsqueda; el destierro de las bibliotecas en los confines de los espacios escolares; y, lo que me parece más decisivo y más trágico: cierta destrucción del pasado.

No quisiera apenas sobrevolar por estas cuestiones. Renegamos de los otros porque no escriben, o porque no escriben con sus propias palabras, o porque no se sueltan, porque no escriben de un modo soberano, no tejen su propio discurso o el discurso resultante nos resulta incomprensible. Pero: ¿cómo sería posible hacerlo? ¿Qué permitiría a otros escribir algo que valiera la pena, que les valiera la pena, que nos valiera la pena?

\section{Escribir como escuchar}

Enseñar la escritura es mostrar la escritura, es verla, revelarla, entregarse a una gestualidad que no reconoce principio, duración, final. La escritura se enseña en la escritura, durante la escritura. Más allá de los métodos, las prácticas, la persistente voluntad o la tentación del desistir, escribir no encuentra una trayectoria lisa, despojada de laberintos, ni una secuencia que admita progresión o culminación: la escritura es ese misterio que permanece escribiéndose a si misma.

En La palabra heredada, Eudora Welty (2012) - escritora a la que se ha comparado con William Faulkner en el espacio de la literatura norteamericana del siglo XX-propone un hondo ejercicio de la memoria: ¿de dónde provienen los primeros sonidos, las primeras lecturas, la relación con lo visto? ¿Qué es lo que hace posible la escritura como inicio de una acción cuyo desenlace se ignora? ¿Cómo se conjugan las experiencias de escuchar y atesorar las palabras, de ser leído y, tal vez, escribir, de mirar hacia lo mínimo, hacia lo que no lleva nombre y nombrarlo una y otra vez?

Nadie sabe cómo se aprende, cómo es posible retener para sí la propiedad de la lengua, qué trayectorias o travesías se vuelven aciertos o desaciertos en la elección de una palabra, una cadencia, una descripción. Ocurre que todo sucede al revés, quizá como recuerdo y no como propagación de una idea, tal vez como un fragmento de una memoria claroscura y no como una intención de voluntad; sucede, quién sabe, con la percepción ulterior de lo imperceptible, y aún así no siempre, no seguramente, no definitivamente. 
Welty recuerda, por ejemplo, los vestigios poderosos del escuchar durante su infancia: escuchar las canciones que silbaban sus padres a través de la escalera de su casa -su madre en la planta baja, su padre en el cuarto de baño-; escuchar a su madre cantando día y noche; escuchar la primera vez en que le fue ofrecida la lectura: "Desde la primera vez que me leyeron, y desde que empecé a leer por mí misma, jamás ha existido un solo renglón que no haya oído" (WELTY, 2012, p. 32).

Escuchar: todo pensamiento nace en otro sitio, en otra soledad, en otra persona. La noche no puede ordenarse a voluntad, ni tampoco los ríos recorren los sitios que deseamos. Una idea cualquiera se sostiene por la fuerza brutal de lo que no tocamos ni miramos, por la banalidad de creer en lo que apenas está frente nuestro o por toda la desidia que se vuelve indiferente a las palabras. ¿Qué pensar, cómo hacerlo cuando uno no va hacia las palabras, sino palabras hacia uno? Escuchar a partir del anuncio de un abismo: lo que creíamos antes no eran más que muletas que se derrumban al caminar. Escuchar como fragilidad: el sentir es primero. Escuchar como temblor de la lengua: uno debería callarse si quisiéramos que algo ocurra.

Recuerda Welty, además, el fino y sinuoso aprendizaje de su mirada: el ver en el sentido de aprender a comprender o, mejor aún, de darse cuenta; aprender a dudar, a percibir la diferencia entre las luces y los volúmenes, las superficies y las tinieblas, la candidez del día y la abrumadora insensatez de la noche.

Mirar: hacer de cuenta que es posible acariciar las rarezas, tocar la parte más esquiva del sol, o la curva del relámpago, o la transparencia de los lados de la lluvia. Mirar con prudencia, para que el tiempo se lleve su propia soledad. Mirar con estupor: como si el deseo estuviera encendido desde antes. Mirar con ternura: como si no hubiera más que infancia. Mirar con sencillez: lo mirado no precisa ser nombrado ni arrastrado. Mirar como acompañar un cuerpo aún indeciso. Mirar para afirmar lo presente, lo que permanece ni muy lejos ni muy cerca: mirar enredado al alrededor. Mirar como lo opuesto de escaparse. Mirar como escuchar.

Recuerda, en fin, el encuentro con la voz, con su propia voz: la emergencia del relato, el descubrimiento de lo decible, la ilógica de las secuencias entramadas con los hechos, la pasión por contar: "La voz reestablece allí la corporalidad, la gestualidad en el modo de significar. El discurso ya no es allí una elección en la lengua, u operadores lógicos, sino la actividad de un hombre que realmente está hablando" (MESCHONNIC, 2007, p. 148).

Encontrar la propia voz: descubrir el propio paso, el propio peso y la propia liviandad, la breve y fugaz medida de los átomos, las circunferencias y las páginas escritas o todavía blancas. Quitarse de uno, de lo que yo se es, de lo que yo se sabe: lo idéntico a sí mismo no provoca sino necedad y hartazgo. Irse al mundo: a las tumbas de los poetas, a los cielos próximos, al pasado menos reciente, a la duración de lo frágil, a los gestos que todavía están inmóviles. La voz como una retirada: irse lejos de casa, lejos de todo punto 
de partida. La voz como respiración: nada se dice en el ahogo. La voz como la huída de la apatía, la tiranía, el vozarrón. La propia voz como el regreso a ese sitio nuestro donde nunca estuvimos antes.

Escuchar, aprender a ver, encontrar una voz: tal la irrepetible secuencia, el sostenido desorden en que la escritura ha encontrado un lugar donde extenderse, hacerse materia, y luego, si fuera el caso, darse a leer: "En primer lugar, hay que escribir, naturalmente. Luego, hay que seguir escribiendo. Incluso cuando no le interese a nadie, incluso cuando tenemos la impresión de que nunca interesará a nadie. Incluso cuando los manuscritos se acumulan en los cajones y los olvidamos para escribir otros" (KRISTOF, 2006, p. 67).

\section{La escritura en sus propias palabras}

Escribir podría significar contar experiencias propias con palabras propias. Pero no parece que sean buenos tiempos para ello, es decir, no existe la certeza -como sí se tenía, quizá, unas décadas atrás- que la escritura sea el modo evidente y eficaz para ese propósito. Aquellos que transitamos por la vida académica somos reprimidos fuertemente al escribir nuestras propias experiencias - en lugar de investigar o estudiar la realidad de otros- en nuestras propias palabras - en lugar de adecuarnos a las palabras en boga.

El discutible modelo de la escritura academicista se ha instalado vertical y transversalmente en el mundo educativo como si hubiera algún provecho decisivo en ello. Ensayar, narrar o contar no parecen ser registros amigables en los días que corren. Por lo tanto no podemos decir que la petición sea razonable o, ni siquiera asequible, cuando la atmósfera en la que se espera que algo ocurra con la escritura y con la lectura se ha vuelto al menos turbia o, directamente, asfixiante.

Si no se trata sólo de escribir lo que nos pasa con nuestras propias palabras, habrá que ir en la búsqueda de otras experiencias y de otras palabras. Pero eso es literatura, me dirán. Y yo responderé que sí, sin dudas. Pero no sólo. En la petición por escribir no caben muchas más opciones: o se trata de un pedido arraigado en tradiciones y racionalidades pedagógicas o, por clara oposición, el pedido es literario, esto es: tocar el límite del lenguaje, tocar sus formas, enclavar la metáfora, la imagen, dar vueltas alrededor de los instantes para que duren más allá de lo posible.

En la escritura hay ausencias y presencias: la ausencia del escritor y la presencia del lector; ausencia del escritor que ya ha dejado la marca de sus trazos y presencia del lector que, en ese instante, comienza su intención de descifrarlos, de hacerlos propios, de transformarlos $y$, entonces, de abandonarse en sus propios rastros de lectura.

Pero: ¿qué es lo que está ausente y qué es lo que se vuelve presente en la escritura? No se trata sólo de una ficción que se opone a aquello que es real y lo simula, lo disfraza, lo evita, sino más bien una provocación creada por la falta de demarcación entre lo que 
hay y no hay, lo que conmueve tanto por lo que se hace presente como por aquello que se escapa. La ausencia y la presencia de la alteridad.

Sin el otro, la escritura está despojada de alteridad. Y despojada de alteridad no hay escritura. La escritura es un acto propositivo que vuelve hacia el otro para que se complete su ficción, aún en lo incompleto de la lengua. La palabra de uno no acaba por delinearse hasta que sobreviene la palabra del otro: "Escribir es un acto que desborda a la obra (...) escribir es dejar que otros cierren por sí mismos la propia palabra de uno, y el escribir no es más que una proposición de la que nunca se sabe la respuesta" (BARTHES, 2003, p. 376).

¿Y qué es el desbordarse más allá y más acá de lo escrito, sino la inauguración de unas presencias hasta aquí ausentes, de presencias que llaman a lo ausente, de presencias que intentan traducir las ausencias? El escritor no cierra la palabra sino que da la posibilidad al otro de cerrarla.

Ya mucho se ha escrito acerca de cómo el lenguaje asume la apariencia de lo ausente. 0 más aún: de cómo el lenguaje torna presente aquello que estaba ausente. O bien: cómo el lenguaje rescata lo ausente de su intraducibilidad y lo vuelve menos opaco, menos difuso. Por eso vale la pena preguntarse cómo es que el lenguaje hace posible una ausencia y cómo hace posible, también, una presencia.

Esta es la doble imposibilidad del lenguaje. Y es, también, su doble potencia.

\section{Escritura como extrañamiento}

Sin extrañamiento, sin perplejidad y, en cierto modo, sin el desvanecimiento del yo no sería posible pensar, ni sentir, no tocar la escritura.

Tener dominio del lenguaje no deja de ser una ilusión, una creencia, pero también una traición hacia uno mismo. ¿Qué anima a la escritura? ¿Qué origina el gesto del escribir sino esa extraña necesidad de traducir como se pueda aquello que excede a la razón, lo que provoca zozobra, lo que desborda, lo que se ignora y se seguirá ignorando?

Lo ajeno, lo otro, es también la distancia necesaria para que algo ocurra: si todo fuera interioridad, si todo tuviera ver con lo que forma parte de uno y es su reino, si cada escritura procede de una voz íntima, certera y confesional: ¿dónde está la extrañeza de lo diferente, de lo que no se repite, de lo que es contingente? ¿Cómo sería posible escribir sin sentir de verdad que es posible mirar, como decía Pessoa, como si fuera por primera vez?

Mirar, pensar, sentir, leer, escribir como si fuera por primera vez. Se trata de ignorar lo que tan mal se ha aprendido sobre la razón de lo escrito, su mísera argumentación, la creencia que algo deba ser necesariamente escrito pues hay otro que lo espera con impaciencia.

Revista Digital do LAV - Santa Maria - vol. 9, n. 2, p. 45 - 60. - mai./ago. 2016 ISSN 1983 - 7348 http://dx.doi.org/10.5902/1983734823512 
Escribir sería no sentir a priori que alguien espera que algo le sea dicho y, mucho menos aún, que seamos nosotros quienes lo escribamos. Tampoco es cuestión de pensar que hay que hacer transparente el mundo para que otros lo comprendan. Carecer de esa vitalidad impune: a nosotros la explicación, a ellos la comprensión. No asumir como propia ninguna noción de posible misión para la enseñanza, la lectura, la escritura.

Pero no dejar de pensar que el mundo ocurre entre brumas y que estamos siempre expuestos en una desnudez extrema. Lo que nos desborda es lo incomprensible y el lugar de fragilidad es el sitio donde nos encontramos.

Escribir, por ejemplo:

Nadie me ha pedido estas palabras. Lo que dicen no proviene ni de un rostro, ni de un recuerdo confundido por el tiempo, ni de ninguna herida expuesta. Se escriben porque sí, porque existe el mientras tanto, porque hay cosas que no son ni están dentro o fuera; son como ese llanto o esa risa que no viene a cuento de nada; hábitos como señuelos de la soledad o como imágenes que se quedaron huérfanas. Hay palabras que se arrojan al aire, palabras que se amarran al suelo y otras que no dicen nada. Sin embargo, alguien podría suponer que son estas las palabras que esperaba, lo que es completamente cierto. Como si llegaran de otro sitio, de otra época. Como si no tuvieran destino, pero sí destinatarios. Palabras que al leerlas crean, entonces, una curiosa memoria nuestra: los trazos de los nombres y de los pájaros, la infancia que se esconde para no ser descubierta, un día entero entre tus ojos, los abuelos que por la noche regresan. Hay palabras que no son preguntas, ni dudas, ni respuestas. A nadie, a ninguno las escribo. A nadie, a ninguno, se le dirá qué hay que hacer, cómo soñar, de que lado del sol o de la montaña está su mundo. Porque de cada uno es el silencio. Y de cualquiera podrían ser estas palabras (SKLIAR, 2014).

\section{Cómo llegar a la escritura}

Si de verdad buscamos respuestas a la pregunta de porqué escribir, hay allí un duelo sin cuartel que se debate entre las razones pedagógicas y las razones literarias. Ya no basta con decir que escribir es importante para el mañana, que escribir sirve para el futuro, que escribir sirve para el trabajo o para la continuidad en el estudio, que escribir garantiza una u otra posición de privilegio. Escribiendo es en presente, no en futuro.

Las razones del escribir están expuestas desde el inicio mismo de la escolarización y la literatura. De un lado, una apuesta por la civilización, la pertenencia cultural, la utilidad, el emblema del sujeto libre, el dominio de la lengua, la identidad, la evaluación, los dispositivos cognitivos, las habilidades, las competencias, el ejercicio, etcétera. De otro lado, la dificultad en soportar el mundo y soportarse, la experiencia del límite, de lo indecible, el enojo con la vida y con lo humano, la agonía de la muerte, la desesperación por decir algo, la rebelión y la desobediencia del lenguaje, la trágica oscuridad, la necesidad de alterar la realidad para poder sobrevivir, etcétera.

Escribir escribiendo, sí. Pero: ¿por qué? ¿Y quién responde? 
Las pedagogías más formales de la escritura tienden hacia una argumentación utilitaria y sus didácticas son modos de convencer a alguien o a todos para que escriban en el marco de un saber ya preestablecido respecto del funcionamiento de la lengua y del texto. Otras pedagogías, quizá más recreativas, abusan de un expresionismo sin fin donde, además, no se avizora ninguna lectura a su alrededor. En ciertos casos la escritura no aparece sino como la contrapartida diagnóstica de una enseñanza previa o como una manera de registro que desaparecerá al día siguiente. En otros casos, es un medio entre el conocimiento anterior, precario, y el conocimiento sucesivo, superior. A veces sobreviene el juego de lo escrito, pero apenas como una suerte de desgano ante la impotencia de no saber cómo dejar la escritura librada a su propia suerte. Otras veces ocurre como prótesis de una comunicación que, en buena parte de los casos, podría resolverse por otros medios.

La argumentación literaria de la escritura no está fuera de ella, no es exterioridad, sino intimidad, una intimidad que puede encontrarse en la revelación misma presente en los textos de los escritores; para dar algunos pocos ejemplos de una lista interminable: se escribe, se está escribiendo porque se quiere defender la soledad en la que se está (por ejemplo, Zambrano, Duras); porque de otro modo el mundo sería lo que es: insoportable (Pamuk); porque es la única invención que sirve para distraernos de la muerte (Elytis); para que el agua envenenada pueda beberse (Maillard); para intentar reparar una desgarradura (Pizarnik); para no dejarse sorprender jamás por el abismo (Cisoux); para saber escribir, porque nunca se sabe escribir (Banville, Neuman); para disimular la incapacidad de hacer otras cosas o por no querer hacer ninguna otra cosa o para no trabajar como oficinista (Vila-Matas); para ponerse del lado de quienes sufren la historia y no de quienes la hacen (Camus); para no comprender y sí para incorporar (Barros); para seguir siendo uno mismo, pero no escribiendo lo mismo (Bernhard); o bien para hacer perdurar el instante (Szymborska, González), etcétera.

Sabemos de la existencia de didácticas que dan cuenta de sus razones pedagógicas y que hacen escribir porque hay que hacerlo o porque es importante para mañana o porque sin la escritura nadie será nada.

¿Pero es posible, entonces, tan siquiera imaginar unas didácticas de la escritura cuyo epicentro se encuentre inexorablemente en la muerte, en la última palabra, en el enfado, en la dificultad por soportar al mundo, en la resistencia, la alteración de lo real, en la soledad, en la desesperación?

La pregunta sigue siendo la misma frente a cada persona nueva, desconocida, anónima o diferente a la que pretendemos ofrecer la escritura. Esa pregunta no es: ¿qué es la escritura?, sino más bien: ¿cómo llegamos a ella? Y no se trata de buenas razones fundadas en las virtudes de testimonios nobles que dan cuenta de cómo ahora saben 
algo que antes no sabían. Es cuestión, más bien, de poder leerlo allí donde la escritura no es código o sistema, sino atravesamiento, encarnadura. Por ejemplo:

¿Cómo llegué a la escritura? ¿No hubiera sido necesario tener primero "las buenas razones" para escribir? ¿Las misteriosas, para mí, esas que le dan a una el "derecho" para escribir? Yo no las conocía. Sólo tenía la "mala" razón, era una pasión, algo inconfesable -e inquietante, uno de esos rasgos de la violencia que me molestaba. No "quería" escribir. ¿Cómo habría podido "quererlo"? Razón, no había ninguna. Había algo de locura. Algo de escritura en el aire a mi alrededor. Siempre próxima, siempre embriagadora, invisible, inaccesible. iEscribir me atraviesa! Me ocurría de repente. Un día estaba acosada, asediada, tomada. Me tomaba. Estaba sobrecogida. ¿De dónde? No sabía nada. Nunca lo supe. En una región del cuerpo. No sé dónde está. "Escribir" me atrapaba, me agarraba cerca del diafragma, entre el vientre y el pecho, un soplo dilataba mis pulmones y dejaba de respirar (CISOUX, 2006, p. 7-8).

No ir a la escritura, entonces, sino llegar a ella. Dejando de lado las buenas razones que asisten a las buenas -y falsas- conciencias; no olvidando nunca de las malas razones, porfiadas e inevitables, que anuncian la escritura en el estremecimiento, en el temblor, en la sacudida, en el sobrecogimiento, en lo inconfesable.

Más acá y más allá del texto -que siempre será incompleto, que necesitará de lectores, sobre el que nunca habrá que darse por satisfecho- escribir es como haber llegado al medio de nuestro propio cuerpo.

\section{Referencias}

BÁRCENA, Fernando. Aprender la fragilidad. Meditación filosófica sobre una excepción existencial. Childhood \& philosophy, Rio de Janeiro, v.8, n.15, jan./jun. 2012.

BARTHES, Roland. El placer del texto y lección inaugural. Buenos Aires: Siglo XXI Editores, 2003.

CANETTI, Elías. El arte de la prosa ensayística. Caracas: Colección Umbrales, Fundación Metrópolis, 1999.

CISOUX, Hèléne. La llegada a la escritura. Buenos Aires: Ediciones Amorrortu, 2006.

DANTZIG, Charles. ¿Por qué leer? Madrid: 451 Ediciones, 2011.

HAUSHOFER, Marlen. La puerta secreta. Madrid: Siruela, 2003.

KRISTOF, Agota. La analfabeta. Barcelona: Ediciones Obelisco, 2006.

LARROSA, Jorge. Fin de partida. Leer, escribir, conversar ( $y$ tal vez pensar) en una facultad de educación. En Maarten Simons, Jan Masschelein \& Jorge Larrosa (editores): Jacques Rancière. La educación pública y la domesticación de la democracia. Buenos Aires: Miño y Dávila, 2011.

LISPECTOR, Clarice. Para no olvidar. Crónicas y otros textos. Madrid: Siruela, 2007. 
MESCHONNIC, Henri. La poética como crítica del sentido. Buenos Aires: MármolIzquierdo Editores, 2007.

SKLIAR, Carlos. Hablar con desconocidos. Barcelona: Editorial Candaya, 2014.

SLOTERDIJK, Peter. Sloterdijk, Peter. Normas para el parque humano. Una respuesta a la Carta sobre el humanismo de Heidegger. Madrid: Ediciones Siruela, 2006.

TRANSTÖMER, Tomas. El cielo a medio hacer. Madrid: Editorial Nórdica Libros, 2010.

WELTY, Eudora. La palabra heredada. Madrid: Impedimenta, 2012.

i Doutorado em Ciências da Recuperação Humana pelo Universidad Del Museo Social Argentino, Argentina (1988). Pesquisador Principal do Facultad Latinoamericana de Ciencias Sociales - Argentina (CONICET/PLACSO). E-mail: skliar@flacso.org.ar.

Enviado em: 30 de maio de 2016.

Aprovado em: 01 de agosto de 2016. 